\title{
Asignatura pendiente: los archivos públicos y el derecho constitucional de acceso a la información
}

\section{Public records and the constitutional right to public information in México: an institutional gap}

\author{
Jaime Hernández Colorado \\ jhcolorado@colmex.mx
}

Director Ejecutivo del Programa Integral de Rendición de Cuentas. Licenciado en Política y Administración Pública por el Colegio de México. Master en Derecho Constitucional. Centro de Estudios Políticos y Constitucionales

\author{
Gabriela Tapia Téllez \\ gabriela.tapia@flacso.edu.mx \\ Profesora Investigadora de la Universidad Autónoma de la Ciudad de México. \\ Doctora en Ciencia Política por FLACSO-México
}

\section{Resumen}

El argumento principal del artículo sostiene que la gestión de los archivos públicos tiene vínculo causal con la rendición de cuentas y que, sin ella, es imposible materializar el derecho de acceso a la información pública. La gestión documental en México es asignatura pendiente y requiere de un programa de reforma que sea consecuente con las modificaciones constitucionales en materia de transparencia y acceso a la información.

\section{Palabras-clave}

Gestión documental, Rendición de cuentas, Archivos, Derecho de acceso a la información, Transparencia.

\begin{abstract}
In this article we argue that public records management is closely related with accountability. That link states that good administration in public archives is a necessary condition for the materialization of constitutional right to public information (the right to know). In Mexico, transparency and the right to access government information have not been understood as superior phases of archive management. Thus, the management of public records has an institutional gap that
\end{abstract}


requires an intensive reform to build an institutional-organizational framework suitable to Mexican laws on transparency and public information.

\section{Keywords}

Archives, Public records management, Accountability, Right to public information, Transparency.

Recibido: $16 / 10 / 2016$

Aceptado: 25/11/2016

DOI: http://dx.doi.org/10.5557/IIMEI7-N13-285307

Descripción propuesta: HERNÁNDEZ COLORADO, Jaime; TAPIA TÉLLEZ, Gabriela, 2016. Asignatura pendiente: los archivos públicos y el derecho constitucional de acceso a la información. Métodos de Información [en línea], 7(13), pp. 285-307.

https://creativecommons.org/licenses/by/4.0/

\section{Introducción}

La rendición de cuentas tiene como elemento de base la gestión archivística. A pesar de su importancia, en este artículo se evidenciará el divorcio conceptual y práctico persistente entre ambos aspectos que afecta significativamente, entre otras cosas, el cumplimiento del derecho constitucional de acceso a la información pública y obliga a que la administración pública se haga cargo de inmediato de esta asignatura pendiente.

Comencemos por enfatizar que los archivos públicos no se integran por documentos, sino por expedientes. Esos expedientes contienen, en teoría, la narrativa de las acciones de los poderes del Estado y de todos los ámbitos de gobierno y son, a la vez, el cuerpo documental en el que se halla la información pública susceptible de ser conocida por el ciudadano. En esos términos, es posible comprender la relevancia de la gestión archivística en el escenario de la administración — sea pública o privada. Llanamente: si no se gestionan correctamente los archivos es como si no existieran y, si los archivos no existen, no puede garantizarse ni mínimamente el derecho de acceso a la información. Así, la gestión documental no sólo es la base primordial para un derecho constitucional, sino, a la vez, es el fundamento para fortalecer la eficiencia de las administraciones. 
El debate académico acerca de renovar la idea que se tiene de la gestión archivística, si bien es cada vez más fuerte, sigue sin tener resonancia suficiente. Empecemos por señalar que la Ley Federal de Archivos (2012) fue el último eslabón de la cadena de construcciones legales-institucionales creadas después de la transición democrática, con el objeto de favorecer su gestión y rendición de cuentas, cuando debió ser el primero. ${ }^{1}$

Además de lo anterior, la Ley General de Transparencia y Acceso a la Información Pública, publicada en el Diario Oficial de la Federación, en mayo de 2015, requiere complementarse con la norma general en materia de archivos, como parte de la estructura normativa para la rendición de cuentas. Hasta el momento, la inexistencia de la ley general limita los alcances del marco normativo, pues existe un desfase jerárquico entre el ámbito de la transparencia y el acceso a la información y el de la gestión documental. La Ley General de Archivos, por ejemplo, se mantiene en proceso legislativo, aunque escrita desde 2014. En un análisis reciente sobre transparencia en las entidades federativas mexicanas se señala que "la categoría de archivos es una de las más débiles a nivel normativo” (Fierro 2014:70) y la respuesta más frecuente en México para negar el derecho de acceso a la información pública es simplemente que la información no existe (IFAI 2013: 83). La inexistencia de la información es una justificación que puede entrañar varios problemas; desde la negativa de la unidad administrativa a dar los datos solicitados, hasta la real inexistencia, pasando por el supuesto que nos interesa: la existencia de la información en soporte documental, pero la incapacidad de la unidad administrativa por encontrarla, clasificarla y entregarla. Esta incapacidad tiene origen en la mala o nula gestión de los archivos.

Como sostiene Ramón Aguilera, urgiendo a la aprobación de la ley general que permanece en proceso legislativo:

"Con la [propuesta de la] Ley General de Archivos se abre un nuevo horizonte para incorporar los procesos, procedimientos y herramientas estandarizados por la archivística contemporánea en los archivos de los tres órdenes de gobierno [y los tres poderes de la Unión]; es decir, establecer un piso común con obligaciones mínimas y con la aplicación 
de una misma metodología que genere un verdadero Sistema Nacional de Archivos. En esta perspectiva los archivos deben ser vistos como verdaderos sistemas de gestión que permitan construir arquitecturas de información útiles a las sociedades democráticas donde juegan un rol relevante para promover la transparencia, permitir el acceso a la información pública y como primer eslabón de la cadena que conforma una política de rendición de cuentas" (Aguilera 2014).

Actualmente existe una Ley Federal de Archivos (LFA) que, por su naturaleza jurídica, obliga a la actuación en la materia sólo a las instituciones públicas del ámbito federal. La necesidad de un marco de carácter general en materia archivística tiene que ver con introducir una lógica técnica clara en la gestión de los archivos en todas las instituciones del Estado mexicano y en todos los ámbitos de gobierno. Sobra señalar que las previsiones de la Ley Federal de Archivos, si bien son una base necesaria, no son suficientes, no sólo porque se ciñen a términos técnicos ya superados, sino porque no se halla — con énfasis suficiente- el vínculo con el derecho de acceso a la información y, en sentido más amplio, tampoco con la capacidad e importancia de los archivos para garantizar una política coherente de rendición de cuentas. Los marcos normativos estatales tienen leyes de archivos que han replicado la redacción de la normativa federal. Sin embargo, la fragmentación de la normatividad y las diferencias entre las disposiciones jurídicas no han permitido que se articule una política integral, existiendo incluso estados que no tienen leyes de archivos, como Nuevo León, Durango y, en el caso de municipios, la fragmentación se hace mayor, pues los reglamentos municipales las más de las veces carecen de lógica técnica —o de lógica, en general—y, en la mayoría de los casos, ni siquiera existen o han sido copiados íntegramente de otros.

Así, la realidad de la gestión archivística en México es poco halagüeña, no sólo debido a la heterogeneidad de los marcos legales, que se traduce en fragmentación de las acciones en la materia y diferencias sustantivas entre cada institución pública respecto de la manera de gestionar sus archivos, sino también porque los esfuerzos en el ámbito federal — centrados en la LFAno necesariamente han influido de manera positiva en el uso de buenas prácticas ni en la mejora de la gestión documental. 
El estudio de la rendición de cuentas es pertinente en el marco político actual, en el cual los escándalos de corrupción han acaparado el debate público —al menos en el caso mexicano-y en el que los índices de percepción de corrupción parecen no moverse a pesar de los esfuerzos institucionales por abatirla. En ese entorno, la importancia de las buenas prácticas en la gestión de los archivos públicos cae por su propio peso. Sin embargo, en México, hasta el momento, la gestión del derecho de acceso a la información pública ha reparado poco en el papel que tienen los expedientes de archivo como pilares esenciales de ese derecho constitucional.

\section{Rendición de cuentas: Archivos y Acceso a la Información Pública}

La rendición de cuentas es un elemento esencial para consolidar y renovar la democracia electoral sobre el tiempo. Es decir, con base en la expresión de la voluntad que se evidencia en los procesos electorales, los gobiernos están obligados a ofrecer a los ciudadanos la máxima disponibilidad y la máxima publicidad de la información que generan, desde la planeación del gasto hasta la fiscalización del ejercicio de ese gasto. La rendición de cuentas, como un marco amplio que integra a varios ámbitos de acción, funciona con base en el derecho de acceso a la información pública. Si bien es posible identificar un cúmulo de prácticas de buen gobierno relacionadas con la rendición de cuentas, la capacidad de dichos ámbitos de efectivamente ser elementos de la rendición de cuentas pasa por el hecho de que los ciudadanos puedan acceder a la información gubernamental.

A pesar de que, hoy en día, la rendición de cuentas, la transparencia y el acceso a la información han aparecido como elementos relativamente novedosos en el horizonte de la Ciencia Política, pertenecen a una discusión académica que tiene larga data, pudiendo incluso rastrearse, en términos teóricos, hasta la etapa del "constitucionalismo revolucionario", que buscó limitar los poderes de los monarcas europeos y hacerlos responsables de sus acciones de gobierno. Sin embargo, ahora más que nunca, la accountability ${ }^{2}-$ como se conoce en inglés a la rendición de cuentas - se ha convertido en un elemento indisoluble de la democracia. 
Como ha señalado Ugalde, "rendición de cuentas es una traducción poco exacta del término anglosajón accountability, que significa ser sujeto a la obligación de reportar, explicar o justificar algo" (Ugalde 2002: 9). En la Ciencia Política se ha discutido suficientemente en diversos sentidos. Vale la pena recuperar el concepto de Luis F. Aguilar, que destaca la responsabilidad ante alguien como elemento esencial de la rendición de cuentas. Esa responsabilidad tiene sentido social y, mucho más importante, jurídico; implica "información obligada (no opcional) e información sobre el cumplimiento o no de una responsabilidad" (Ugalde 2002: 12). La obligación es un elemento central en la definición de Aguilar, pues, considerar que la rendición de cuentas puede ser opcional vacía de contenido al concepto. Esto tiene que ver con la idea de que todos los regímenes políticos, de alguna u otra forma, ejercitan la rendición de cuentas. Las diferencias son de grado. Así, en una democracia, la rendición de cuentas no puede considerarse un elemento prescindible o gradual, en tanto se considere a la democracia representativa como el gobierno que emana del cuerpo ciudadano. En ese sentido, los representantes deben responsabilizarse obligatoriamente ante ese cuerpo electivo (Ugalde 2002: 13).

Es posible entender, según la definición de Subramaniam, que el concepto de accountability se refiere a la "rendición de cuentas respecto del dinero público, responsabilidad pública de los políticos respecto del uso que hacen del poder del gobierno, y, capacidad de los servidores públicos para diseñar políticas que no sólo hagan eficiente el gasto, sino que lo dirijan a resolver necesidades ciudadanas" (Subramaniam 1983: 446-456). Esta propuesta conceptual es sumamente interesante, pues amplía las consideraciones que se han elaborado desde la Ciencia Política, dándole a la rendición de cuentas un enfoque de gobernanza, pero también incluyendo una visión de Administración Pública.

La rendición de cuentas se presenta como un muro contra aquellas prácticas que pueden minar - y lo hacen de hecho- a la democracia. Es sencillo identificarlas y pueden resumirse diciendo que son aquellas que, por un lado, atentan contra la idea de buen gobierno y, por otro, contra la propiedad de los bienes públicos. En estas ideas pueden englobarse con claridad los comportamientos a los que se opone la rendición de cuentas. Es claro que esas conductas no sólo afectan la calidad democrática de un país, sino también 
minan la legitimidad y la confianza de los ciudadanos en los gobiernos y en la manera de elegirlos (Moncrieffe 1998: 388).

En la propuesta de Morlino sobre las características de una "buena democracia" (good democracy) se incluyen cinco dimensiones. Como señala el autor, una "buena democracia" puede variar en esas dimensiones. Una de ellas, la segunda, es precisamente la rendición de cuentas, a la que Morlino considera una dimensión "procedimental". Es posible entender que esa condición "procedimental" otorga a la rendición de cuentas la capacidad de profundizar y, sobre todo, mantener en el tiempo la cualidad democrática de un régimen de gobierno. Es decir, de renovar o revitalizar constantemente el acuerdo que los electores tomaron en las urnas. En palabras llanas, el triunfo en una elección no es un cheque en blanco para los representantes (Morlino 2002: 4-5).

Una consideración relevante de la argumentación de Morlino es que son difíciles de introducir las modificaciones institucionales y legales para hacer posible la rendición de cuentas, pues se enfrentan a la resistencia de los cuerpos burocráticos (Morlino 2002: 9). Sin embargo, al menos para el caso mexicano, si bien las características de la burocracia impiden cambios espectaculares, es posible implantar modificaciones, pues la relación entre burocracias y liderazgos ha sido tangencial, debido a que la mediación, históricamente, ha sido entre los liderazgos y la población. ${ }^{3}$ En ese esquema, las burocracias en México han funcionado como correas de transmisión subordinadas al líder. Sin demérito de lo que la teoría política ha dicho sobre la rendición de cuentas, la trayectoria política mexicana tiene como elemento esencial el control que los liderazgos pueden ejercer sobre las burocracias. $\mathrm{He}$ ahí una ventana de oportunidad para el cambio institucional.

La democracia no se agota en las elecciones. La construcción de la legitimidad de las instituciones públicas es un proceso constante y de suma complejidad, que interrelaciona la eficiencia de las acciones gubernamentales, con la calidad en el ejercicio del gasto público y, finalmente, con la publicidad de toda esa información, amén de la relación estrecha y permanente con los ciudadanos. El vínculo entre democracia y rendición de cuentas no termina una vez que las personas han emitido su voto, aunque sí es el mecanismo que tienen los 
ciudadanos para premiar o castigar el desempeño de los oficiales públicos. Más allá de la rendición de cuentas 'política', la accountability se refiere, como se ha señalado, a varias aristas de responsabilidad (Moncrieffe 1998: 391).

La rendición de cuentas, como una de las dimensiones de una "buena democracia", se puede descomponer en tres vertientes: información, justificación y castigo/compensación. Morlino recupera esta división de Schedler, quien las entiende como características de la rendición de cuentas (Morlino 2005: 9). En ellas se puede identificar claramente los elementos que hemos deslizado hasta ahora. Primero, el derecho de acceso a la información gubernamental. Segundo, la responsabilidad respecto del ejercicio de un encargo público específico. Tercero, la obligación y vinculación respecto de la forma en que se ejerce la representación. En el fondo puede observarse el elemento que Aguilar considera esencial: la obligación jurídica.

Las acciones de un gobierno pueden - $\mathrm{y}$ deben - ser evaluadas por los ciudadanos en ámbitos distintos: desde las decisiones políticas acerca de algún tema, hasta la ejecución del gasto público, pasando por la planeación, desempeño y demás aspectos de los programas públicos. Como elementos transversales a todas esas etapas del ejercicio de las atribuciones públicas, se encuentran los archivos y el acceso a la información. Así, es posible asentar que la rendición de cuentas tiene varias vertientes, y, por otro lado, que está en la base de una democracia, pues ofrece medios para que los ciudadanos conozcan, con toda eficiencia, cuáles y cómo son las acciones gubernamentales. La rendición de cuentas ha entrado como elemento constante en el discurso político como elemento de legitimación, aunque poco frecuente en la realidad (Borowiak 2007: 998).

En este sentido, como reconocen López Ayllón y Merino, "una democracia no podría contar con una base sólida para su consolidación en el largo plazo sin un sistema de rendición de cuentas" (López Ayllón 2009: 7). Sin embargo, la idea de rendición de cuentas no puede reducirse a su asimilación con la discusión sobre la democracia. Como sabemos, la rendición de cuentas puede entenderse en dos niveles o ámbitos distintos. Aquella conocida como rendición de cuentas vertical es la que se da entre sujetos jerárquicamente desiguales. El otro nivel, conocido como rendición de cuentas horizontal es 
aquel que se desarrolla entre sujetos jerárquicamente similares — que pueden ser instituciones- (López Rubí Calderón 2007: 184).

Como hemos señalado, la identificación de la rendición de cuentas con un régimen democrático o, más concretamente, con la idea de "good democracy" de Morlino, remite a una idea de procesos. Es decir, entendemos a la rendición de cuentas como un concepto multidimensional que, de forma transversal, puede fortalecer - $\mathrm{O}$ debilitar, en caso de estar ausente - la democracia a través de la relación permanente entre el gobierno y los ciudadanos.

Relacionado con esto, es necesario hablar sobre un elemento más, connatural a la rendición de cuentas, que es la participación ciudadana en algunos ámbitos de la acción de gobierno. Si bien ha quedado claro que la publicidad de la información y la transparencia permiten la observación de los ciudadanos y eso, por sí mismo, genera legitimidad a los gobiernos, la integración de los ciudadanos a la participación directa en ciertos ámbitos de la vida pública, mediante cuerpos de acompañamiento, observación y/o consejo, ofrece un respaldo sin igual las decisiones gubernamentales (Moncrieffe 1998: 402).

En este punto, la rendición de cuentas se entiende también como elemento que garantiza la convivencia sana entre ciudadanos e instituciones gubernamentales, en una idea que dirige al concepto de gobernanza. Esa relación estrecha - $-\mathrm{y}$, sobre todo, seguimiento- que se da entre los ciudadanos y el gobierno permite a éste avanzar en el cumplimiento de las expectativas de gobernanza de sus ciudadanos. Es decir, en este punto, la responsabilidad intrínseca que implica el concepto de rendición de cuentas no sólo es de parte de los gobernantes, sino de una ciudadanía que monitorea el ejercicio del gasto público y, en general, los actos de los representantes elegidos para hacerse cargo de las labores del gobierno (Diamond y Morlino 2005: XI-XII). La rendición de cuentas, con la claridad que ofrece sobre las decisiones públicas y, en general, sobre las acciones de las instituciones del Estado, es "la expresión administrativa fundamental de la democracia" (RRC 2014-2018). Siguiendo con esta idea, esa expresión administrativa se plasma en actos de esa misma naturaleza, los cuales tienen consecuencias jurídicas. Esos actos administrativos, que tienen la capacidad para modificar los resultados de las acciones de las instituciones del Estado, no sólo se verifican en el tiempo, sino que se plasman en documentos públicos que, reunidos, se transforman en 
expedientes que, a la vez, se integran en los archivos. De ahí que la importancia de considerar a los archivos elemento esencial de la rendición de cuentas no sólo se sostiene en una base de lógica administrativa, sino también se sustenta en el sentido procedimental de la democracia. Si la rendición de cuentas es el fin esencial, pues renueva el pacto entre los representantes y los representados, la buena gestión archivística y el acceso a la información deberían ser el medio para llevarlo a cabo.

Las solicitudes de información, por medio de las cuales se materializa en México el derecho constitucional de acceso a la información pública, ofrecen el ejemplo más pertinente para caracterizar la importancia de las buenas prácticas en la gestión archivística. Para dar respuesta a una de esas solicitudes, cualquier unidad administrativa debe hacer una búsqueda exhaustiva de los datos que pide el solicitante. Ese proceso puede concluir en dos opciones: o se entrega la información o se declara la inexistencia de la información. El análisis de las respuestas a solicitudes de información del INAI (antes IFAI), entre 2005 y 2014, muestra que en promedio la respuesta "información no existe" es del 6.5\% (INAI 2014).

Cuando se declara la inexistencia de la información, también caben dos posibilidades: o la autoridad actúa de mala fe —situación de suyo lamentable_ _ o argumenta la inexistencia de la información porque, en efecto, ésta no existe. Esta última posibilidad tiene resonancias graves. La inexistencia de la información habla de dos situaciones: o los actos de la unidad administrativa en cuestión están llevándose a cabo alejados del derecho administrativo o, pese a que se están desarrollando en apego estricto a la legalidad, caen en el vacío debido a la mala —o nula- gestión documental. Todas estas posibilidades delinean varias vertientes de acción. Sin embargo, el supuesto que suele ser común es el de la inexistencia de información, pero no el de la mala fe, sino el de la falta real de la información. Ese problema tiene una solución lógica: la buena gestión archivística.

A simple vista, la discusión parece una concatenación sencilla de situaciones y supuestos. Lo grave, al menos al analizarlo desde el ámbito académico, es que esas situaciones y supuestos se materializan cotidianamente en las instituciones del Estado mexicano. Y, aún más grave: la respuesta a los muchos problemas que limitan la materialización del derecho constitucional de acceso a la 
información pública y, en general, a la rendición de cuentas, tienen solución en las buenas prácticas en la administración de los archivos.

\subsection{Archivos y el Derecho de Acceso a la Información Pública en el horizonte de la rendición de cuentas}

Una vez que se han señalado los términos conceptuales de la rendición de cuentas es conveniente establecer los vínculos entre ésta, la gestión archivística y el derecho de acceso a la información pública. En la propuesta teórica de Mauricio Merino, que entiende a la rendición de cuentas como una "cadena" cuyos eslabones iniciales son los archivos y la gestión de la información pública, se entiende bien lo que se ha expuesto: para que exista rendición de cuentas deben existir dos condiciones insustituibles: una adecuada gestión de los archivos públicos, enlazada con la gestión de la información pública (RRC 2014-2018).

Los archivos son la columna vertebral y la piedra fundacional de la estructura de la rendición de cuentas. A la par de la transparencia, la gestión archivística es un elemento transversal a todas las etapas del ejercicio del gobierno y, en general, de la ejecución de las atribuciones de todas las instituciones públicas. La gestión de los archivos - y, sobre todo, la buena gestión, es decir, las buenas prácticas - permite articular una estructura de información que tiene impacto en dos vertientes: la interna y la externa. En lo interno, los archivos bien gestionados permiten concentrar datos y ofrecer herramientas para la toma de decisiones, la evaluación de las acciones, políticas y programas públicos y, en general, para el buen curso de las instituciones públicas. En el sentido externo, los archivos constituyen la "arquitectura" necesaria para dar cumplimiento al derecho constitucional de acceso a la información pública, sea por medio de la respuesta a las solicitudes ciudadanas o de la publicación proactiva de la información pública (Aguilera 2014: 5).

El marco normativo de transparencia y acceso a la información pública en México, desde su primera versión, contiene la previsión de que la información contenida en los expedientes de archivo es de carácter público y debe estar a disposición de los ciudadanos, siempre que no encuadre en los presupuestos 
de reserva que señala la propia normatividad. De esta forma, el entrelazamiento de la gestión de los archivos y el acceso a la información pública no sólo es un supuesto teórico, sino una simbiosis reconocida por el marco jurídico nacional en México.

La concepción que es urgente renovar es aquella que entiende a los archivos como un cuerpo documental que sólo contiene evidencias y testimonios útiles para la investigación académica. Esa idea es correcta para los archivos históricos que, por la naturaleza de su adjetivo, tienen características específicas. Pese a su importancia, los archivos históricos no deben eclipsar el resto de las vertientes de acción de la ciencia archivística, pues, los expedientes que los integran alguna vez fueron de trámite o de concentración. Es conveniente recuperar la condición bifronte de los archivos que propone Aguilera, a fin de caracterizarlos conceptualmente en su complejidad real. Según ese autor, los archivos tienen dos condiciones inherentes: por un lado, conservan —-mediante una organización estricta - las evidencias de los actos de las instituciones del Estado, y, por otro, debido a esa primera condición, constituyen una fuente de información en dos ámbitos: para la organización que los produce y para la sociedad en su conjunto (Aguilera 2014: 2).

El vínculo entre la gestión de los archivos y el acceso a la información termina de entenderse cuando se tiene en cuenta que las administraciones actuales guardan, por obligación jurídica, evidencia de cada una de sus acciones. En sentido normativo, los archivos son constancia de los actos de autoridad y administrativos. Así, la gestión archivística —es decir, las buenas prácticascontribuye a: "1. una adecuada gestión administrativa, pues sirve de evidencia de las acciones de los gestores; 2. como herramienta de control interno de los procesos administrativos, y; 3. como instrumento eficaz para la rendición de cuentas" (Aguilera 2014: 6).

En suma, la comprensión del nexo entre los archivos y el acceso a la información es la base para sostener la idea principal de este trabajo. Si la rendición de cuentas, en un punto, es puramente transparencia y acceso a la información — pues los gobiernos rinden cuentas a los ciudadanos, que se enteran de los actos gubernamentales mediante la publicidad de la información—, esa traducción mínima la convierte en dependiente directo de 
la buena gestión archivística. Como dice el proyecto de norma española ISO 15489-1, marco técnico internacional de gestión documental:

\begin{abstract}
"Los documentos de archivo contienen información que constituye un recurso valioso y un activo importante de la organización. La adopción de un criterio sistemático para la gestión de documentos de archivo resulta esencial para las organizaciones y la sociedad, a fin de proteger y preservar los documentos como evidencia de sus actos. Un sistema de gestión de documentos de archivo se convierte en una fuente de información sobre las actividades de la organización que puede servir de apoyo a posteriores actividades y toma de decisiones, al tiempo que garantiza la asunción de responsabilidades frente a las partes interesadas presentes y futuras" (Comité Técnico Normalización 50 de AENOR 2005: 92).
\end{abstract}

\title{
3. La gestión de los archivos públicos: líneas fundamentales
}

Es necesario puntualizar los términos en que se debe llevar a cabo la gestión documental, a la luz de la importancia de ésta para la rendición de cuentas y como mancuerna/garante del derecho de acceso a la información pública. De entrada, es correcto decir que los archivos públicos deben gestionarse, al igual que aquellos de carácter privado, a partir de la característica que los defina.

\subsection{Tipos de archivos}

La tipología de los archivos, más allá de ser una definición de carácter técnico, tiene sustento en los documentos normativos que rigen hoy en México ${ }^{4}$. Los archivos son: de trámite, de concentración e históricos. El orden de importancia no es trivial, pues la categorización de los archivos tiene que ver con el cambio de paradigma que es urgente en la administración mexicana. Las categorías que se mencionan en este apartado no solamente se refieren a unidades de gestión — que menciona la legislación mexicana—, son, en sí mismas, tipos que tienen que ver con la naturaleza y situación de los archivos. Es decir, todos los expedientes de archivo pasan por esas tres categorías, que 
son etapas de su vida útil. En algún espacio temporal, todos los expedientes de archivo son de trámite, de concentración o históricos, si bien existe la posibilidad de que sean desechados, en lo que se denomina archivo muerto. Sobra agregar que el concepto de archivos generales engloba a los archivos de concentración y a los archivos históricos, aunque tradicionalmente, debido al paradigma de gestión que prima en México, ese término designa a archivos históricos. Por tanto, parte del viraje que se considera necesario en el paradigma de la administración de los archivos en México es dejar atrás ese concepto de archivo general - que suele convertirse en el epónimo de la desorganización archivística- y denominar a cada cuerpo documental por sus características temporales.

Los archivos de trámite son aquellos expedientes cuya integración aún no ha concluido. Se caracterizan por la necesidad de ser tratados con el mayor cuidado posible, pues eventualmente se integrarán al siguiente cuerpo documental (de concentración). La importancia de estos archivos radica en su condición de estar en formación, pues exige la consulta constante por las unidades administrativas. En ese sentido, los archivos de trámite suelen ser tratados por los funcionarios públicos y por el personal de apoyo, lo cual no implica que sean éstos quienes deben gestionarlos — pues no tienen la obligación de tener formación profesional en materia archivística. La condición inacabada de los archivos de trámite también requiere que, físicamente, se encuentren a disponibilidad de las unidades administrativas y, a la vez, que los espacios físicos en que se almacenan sean adecuados a la gestión, que debe llevarse con bases técnicas. Una vez que los asuntos de un expediente que está en el archivo de trámite se dan por concluidos, éste se integra al archivo de concentración.

Los archivos de concentración se forman con aquellos expedientes que, pese a ser evidencia de actos administrativos o actos de autoridad que ya han causado estado, siguen siendo materia de consulta, sea para la toma de decisiones o sea para dar respuesta a solicitudes de acceso a la información. Es conveniente notar que los archivos de concentración son el cuerpo documental más numeroso de cualquier institución pública, pues no tienen aún la antigüedad suficiente para ser archivos históricos y su relevancia para los asuntos cotidianos sigue siendo alta. Las exigencias para la gestión de los archivos de 
concentración tienen que ver con la profesionalización de sus gestores, la coherencia técnica de su organización y el acondicionamiento físico de espacios que cumplan los requerimientos ambientales de la buena gestión documental. Por tanto, la administración de los archivos de concentración no es tarea sencilla, pero, por la importancia que tienen y el vínculo entre éstos y el derecho de acceso a la información, son materia insoslayable para las instituciones del Estado. Por el diseño constitucional del derecho de acceso a la información y las previsiones del marco jurídico — ahora general, con la Ley General de Transparencia y Acceso a la Información Pública-, los archivos de concentración son la materia más importante, pues son la fuente principal de la información.

Los archivos históricos se integran de aquellos documentos que, por su naturaleza y situación temporal, han dejado de ser relevantes para la consulta esporádica, aunque siguen siendo considerados importantes tanto para las unidades administrativas como para los ciudadanos y, en suma, para la memoria administrativa, política y social, pues son evidencia de actos administrativos y de autoridad de épocas pasadas. Es necesario mencionar que el paradigma actual de la gestión archivística en las instituciones públicas mexicanas remite a los archivos históricos. Ha sido - y sigue siendo muy complicado- establecer la idea de que los archivos de trámite y de concentración requieren incluso de mayor atención que los archivos históricos en México, pues su situación ha sido de desventaja. Es innegable que su importancia tiene que ver con la buena gestión y con la rendición de cuentas. Esto no quiere decir que los archivos históricos sean poco importantes, pero sí que la situación de la administración de éstos es menos preocupante que la de los otros dos.

No es trivial la tipología de los archivos, pues debe tenerse en cuenta que esos tres conceptos no sólo describen la naturaleza de los expedientes en distintos momentos de su vida útil, sino, a la vez, ofrecen herramientas para diseñar una política de gestión documental adecuada a las necesidades de cada bloque archivístico. Los tipos de archivos tienen que ver, como se ha señalado, con la etapa de la vida en la que se encuentra cada expediente. Esta propuesta conceptual fue desarrollada a finales de la década de los noventa y se denomina "records continum concept", es decir, la idea de la continuidad del 
documento, que remite a lo que aquí se ha denominado "etapas de la vida útil" de los expedientes. La propuesta de Frank Upward tiene como base que "no existen etapas separadas en la vida de los documentos, sino que su gestión debe ser asimilada como un proceso continuo" (Aguilera 2002: 7). Como se ha afirmado párrafos arriba, este "modelo inclusivo" — como lo llama Aguilera - tiene que ver con entender a los expedientes como "instrumentos de gobernanza y rendición de cuentas; como formadores de memoria e identidad y como fuentes de información cuyo valor añadido lo dan sus cualidades probatorias, su transversalidad y su contextualidad" (Aguilera 2002: 8). Aguilera sostiene, además, una idea que termina de dar fortaleza a los planteamientos que se han hecho en este artículo sobre la simbiosis archivosrendición de cuentas:

"En esta visión [la de Upward], los documentos no pueden ser categorizados como prueba (archivos administrativos) o como memoria (archivos históricos), sino que son ambas cosas. Es su naturaleza probatoria la que los distingue de otras formas de información documental y les permite jugar un rol especial en la formación de la memoria, en una doble vertiente: como recuerdos que construyen la identidad individual y corporativa, y como promotores de la responsabilidad que los actores tienen frente a la sociedad. Este enfoque [el de la continuidad del documento] nos permite comprender mejor la función de los archivos dentro del núcleo duro de un sistema de rendición de cuentas".

\subsection{Necesidades para una buena gestión}

Teniendo como base la descripción de la tipología de archivos, es posible desarrollar algunos planteamientos dirigidos a identificar áreas de oportunidad y, a la vez, a delinear los cambios que son urgentes en el sistema de gestión de archivos en México. La capacidad renovadora de la reforma en materia de transparencia y acceso a la información —de 2015—, pone bases suficientes para integrar en sus cambios también aquellos relacionados con la gestión documental. Empero, el campo de acción de las instituciones públicas para renovar y fortalecer los sistemas de administración de archivos es sumamente 
amplio y no se circunscribe a modificaciones normativas. Las normas, por más especializadas y perfectas que sean, no pueden cambiar el paradigma de gestión, pues sólo colocan las bases sobre las que deben articularse las acciones de carácter organizacional y técnico. Aun así, un marco normativo general en la materia es la primera necesidad para un nuevo - y funcionalsistema nacional de archivos.

"La gestión documental es un proceso que tiene como finalidad asegurar una atención apropiada a los documentos creados o recibidos por una organización como prueba de las actividades realizadas y preservarlos durante el tiempo que sean necesarios. Por eso, un sistema de gestión de la organización que no contemple la buena gestión de los documentos quedará incompleto, por cuanto deja de lado un activo fundamental para cualquier organización" (Alonso 2008: 15).

Sobra señalar que las premisas que se desarrollan a continuación son necesarias para el buen rumbo de los archivos en todas las instituciones del Estado mexicano. Sin embargo, tanto los poderes de la Unión como dependencias y entidades del Poder Ejecutivo y todos los ámbitos de gobierno tienen a la mano, hoy, herramientas para introducir los cambios que se consideran urgentes en esta materia. No es necesario que el cambio de paradigma del que se ha alertado se convierta en una obligación jurídica, a través de una ley general, lo preciso es que las instituciones del Estado asimilen los rezagos que hay en términos archivísticos. Desafortunadamente, la experiencia histórica demuestra que los cambios estructurales en México requieren convertirse en obligaciones jurídicas para materializarse, pues las acciones de mejora continua son poco frecuentes en las estructuras institucionales.

Para la buena gestión archivística, en México se requiere de un marco general —es decir, una ley general - que obligue a todos los ámbitos de gobierno y a todas las instituciones del Estado al cumplimiento de criterios especializados. En el marco actual, el resultado del Diagnóstico de Archivos del INAI (2007) concluye que existe una brecha entre la normatividad establecida en los lineamientos generales para la organización y conservación de los archivos y el cumplimiento real de dichas disposiciones (IFAI 2008: 13). 
Las condiciones del marco general deben ser:

- Exhaustividad: buscando agotar todos los supuestos susceptibles de debilitar la capacidad del sistema nacional de gestión de archivos.

- Técnica: buscando diseñar un marco perfectible de gestión que, al ser obligatorio a todas las instituciones públicas y a todos los ámbitos de gobierno, permita dar coherencia técnico-profesional a los archivos públicos de todo el Estado mexicano.

- Innovación: buscando integrar en el marco técnico-profesional no sólo las mejores prácticas archivísticas, sino también las más recientes, pues las tecnologías de la información y comunicación han abierto un cúmulo de posibilidades para la administración y tratamiento de los archivos.

- Homogeneidad: buscando imponer un marco general de gestión de los archivos públicos en México, de forma que, al empatarse con la gestión del acceso a la información pública, la lógica única en materia archivística facilite - y garantice- el cumplimiento de ese derecho constitucional, en lugar de complicarlo.

La existencia de una base normativa no es condición suficiente para la implementación de una política integral, coherente y, sobre todo, nacional, de gestión documental. El marco legal debe proveer, a la vez, las características sobre las cuales se articulará el marco organizacional para la administración de los archivos. La participación de las instituciones y de los cuerpos burocráticos es condición necesaria para llevar a cabo cualquier política pública. Al tener la naturaleza de política de Estado, la de la gestión archivística debe involucrar adecuaciones funcionales en todas las instituciones públicas, de suerte que sea posible que las estructuras institucionales atiendan — de la mejor forma posible_ las obligaciones que les reserve el nuevo marco legal.

Al hablar de la necesidad de un contexto organizacional suficiente, evidentemente se remite a la urgencia de que todas las instituciones del Estado mexicano cuenten con áreas dedicadas exclusivamente a la gestión de archivos y que, al tiempo, haya realmente una estructura administrativa para el sistema nacional de archivos, es decir, una instancia coordinadora, rectora e impulsora 
de los esfuerzos en materia archivística que, al menos, tenga existencia permanente por medio de una secretaría técnica.

En el diagnóstico citado, en el que participó el 73.4 por ciento de las dependencias y entidades de la Administración Pública Federal, se observa que "sólo alrededor del 20 por ciento de los responsables del área coordinadora de archivos se dedican de tiempo completo a la labor archivística y los programas de incentivos para mejorar los archivos son prácticamente inexistentes (IFAI 2008: 12). Por tanto, la profesionalización del cuerpo funcionarial que gestione los expedientes de archivo es condición necesaria para la implementación de buenas prácticas en la materia.

Aunado a lo anterior, una parte importante de los problemas actuales en el tratamiento de los archivos públicos derivan de la incapacidad técnica de los funcionarios que los administran. Esa incapacidad no es achacable, sin embargo, a esos funcionarios, pues las atribuciones de éstos no necesariamente engloban a la gestión documental. La poca presencia de especialistas en archivos en las instituciones públicas en México, tiene que ver con el paradigma que hemos expuesto: la mayoría de los profesionales archivistas se han forjado en la administración de archivos históricos, con técnicas que han sido superadas y teniendo como idea esencial la separación de los archivos respecto de cualquier otro ámbito público: la rendición de cuentas y el derecho de acceso a la información, los más importantes.

La profesionalización de los funcionarios también es una vertiente que debe insertarse en el diseño normativo, pues la exigencia de conocimientos especiales para ocupar los puestos de gestión de archivos no es un elemento generalizado en el cúmulo de normas sobre archivos que existen en México.

\section{Consideraciones finales}

Para concluir, viene bien puntualizar que, como hemos dicho, con todas sus desventajas técnicas, la actual Ley Federal de Archivos no es una camisa de fuerza que limite la capacidad de las instituciones del Estado mexicano para llevar a cabo acciones de mejora e innovación de la gestión. En ese entendido, 
la inacción en gestión documental se puede achacar a tres factores: (1) la falta de desarrollo de la ciencia archivística en México, que limita el acompañamiento que podrían hacer los profesionales en la materia, pues la nómina de los archivistas expertos sigue siendo mínima en relación con el tamaño de las áreas de oportunidad; ${ }^{5}$ (2) la falta de prioridad a la actividad archivística en las instituciones públicas mexicanas, es decir, existe una carencia de atención al tema que se traduce en poco interés por desarrollar proyectos de mejora y que, a la vez, se convierte en poca atención presupuestal a la gestión documental, y; (3) la resistencia de los cuerpos burocráticos a los cambios, que tiene su origen en dos dinámicas que son frecuentes en las instituciones mexicanas: la abulia por llevar a cabo innovaciones y acciones de mejora, si éstas no son ordenadas por medio de modificaciones al marco jurídico, y, la positivización excesiva del marco de atribuciones de las instituciones del Estado mexicano, lo cual ha llevado a que los cuerpos burocráticos —ante el cúmulo de actividades que deben hacer para cumplir la ley - elijan limitarse a desarrollar esas actividades, cancelando la posibilidad de llevar a cabo otras que, si bien no las ordena ni limita la ley, podrían tener efectos positivos y, en suma, mejorar la gestión pública.

Empero, las necesidades que hemos señalado se resumen en la urgencia por aprobar la Ley General de Archivos y, al mismo tiempo, por el viraje en el paradigma dominante de gestión de archivos en México, para incluir una nueva priorización de la gestión documental. Las acciones de mejora e innovación en la gestión de los archivos en México no sólo requieren de un marco normativo novedoso sino de voluntad política $y$, sobre todo, administrativa, pues, hasta ahora, pese a que el marco jurídico en la materia no es limitativo, la buena gestión de los archivos públicos —moderna, eficiente, eficaz y apegada a la técnica— sigue siendo una asignatura pendiente.

\section{Notas}

1. Entre las instituciones creadas posterior a la transición a la democracia se encuentran la Auditoría Superior de la Federación (ASF), el Instituto de Acceso a la Información Pública (IFAI), la Ley del Servicio Profesional de Carrera, la Secretaría 
de la Función Pública, el CONEVAL, el Sistema de Evaluación del Desempeño y por último el Sistema Nacional de Archivos en el 2012. Mauricio Merino, "La segunda transición democrática de México: Esfuerzos, tropiezos y desafíos de México en busca de un sistema completo, articulado y coherente de rendición de cuentas”, 2012, Washington, Wilson Center-Comexi, www.wilsoncenter.org, p. 2.

2. Término cuyos alcances teóricos son muy amplios. Llegan, incluso, más allá del propio ámbito del gobierno y han tenido especial importancia en el campo de las relaciones comerciales, siendo de gran importancia el concepto de rendición de cuentas en la empresa, estrechamente relacionado con la idea de eficiencia.

3. Véanse: Mauricio Merino, Gobierno local, poder nacional, 1998, México, El Colegio de México y Fernando Escalante Gonzalbo, Ciudadanos Imaginarios, 1993, México, El Colegio de México.

4. Véase la conceptualización que se incluye en el artículo 4 de la Ley Federal de Archivos.

5. Problema del que alertan algunos autores y que tiene que ver no sólo con la poca presencia de especialistas en la materia, sino con su poco activismo público para transmitir la importancia de la materia de la que se ocupan. George Mariz et al., "Leadership skills for archivists", The American Archivist, vol. 74, núm. 1, 2011.

\section{Bibliografía}

AGUILERA MURGUÍA, Ramón, 2014. Archivos: Un componente indispensable del sistema de rendición de cuentas. México: Red por la Rendición de Cuentas-CIDE. ISBN: 978-607-9367-11-4.

AGUILERA MURGUÍA, Ramón, 2014. Por una moderna y operativa ley general de archivos. El Financiero [en línea]. Disponible en: http://www.elfinanciero.com.mx/opinion/por-una-moderna-y-operativa-leygeneral-de-archivos.html

ALONSO, José Alberto et al., 2008. La norma ISO 15489: un marco sistemático de buenas prácticas de gestión documental en las organizaciones. Revista Ítem, 47. 
BOROWIAK, Craig T., 2007. Accountability Debates: The Federalists, The AntiFederaists, and Democratic Deficits. Journal of Politics, 69(4). ISBN: 1468-2505.

COMITÉ TÉCNICO DE NORMALIZACIÓN 50 de AENOR, 2005. Proyecto de Norma Española UNE ISO 15489. Revista Española de Documentación Científica, 28(1). ISSN: 1998-4621.

DIAMOND, Larry y MORLINO, Leonardo, 2005. Assesing the quality of democracy, Baltimore. The Jonhs Hopkins University Press-The National Endowment for Democracy. ISBN: 9780801882876.

ESCALANTE GONZALBO, Fernando, 1993. Ciudadanos Imaginarios. México: El Colegio de México.

FIERRO, Ana Elena et al., 2015. Métrica de la Transparencia 2014. México: CIDECOMAIP.

INAI, 2014. Informes de Transparencia (2003-2014) [en línea], [Consultado: 23/08/2016]. Disponible en: http://inicio.ifai.org.mx/SitePages/Informes-2014.aspx.

INSTITUTO FEDERAL DE ACCESO A LA INFORMACIÓN Y PROTECCIÓN DE DATOS (IFAI), 2013. 10 años de transparencia en México. México: IFAI. ISBN 978-607-716-015-1.

INSTITUTO FEDERAL DE ACCESO A LA INFORMACIÓN Y PROTECCIÓN DE DATOS (IFAI), 2008. Diagnóstico de Archivos 2007. México: IFAI. ISBN-13: 978-968-5954-37-2.

LÓPEZ AYLLÓN, Sergio y MERINO, Mauricio, 2009. La rendición de cuentas en México: Perspectivas y Retos. México: Secretaría de la Función Pública.

LÓPEZ RUBÍ CALDERÓN, José Ramón, 2007. Acceso a la información pública: una incógnita para especialistas en rendición de cuentas en las democracias. Iberoamericana. Nueva Época, 26. ISSN: 1577-3388.

MARIZ, George et al., 2011. Leadership skills for archivists. The American Archivist. 74(1). ISSN: 0360-9081. 
MERINO, Mauricio, 1998. Gobierno local, poder nacional. México: El Colegio de México. ISBN: 968-120862-5.

MERINO, Mauricio, 2012. La segunda transición democrática de México: Esfuerzos, tropiezos y desafíos de México en busca de un sistema completo, articulado y coherente de rendición de cuentas [en línea]. Washington: Wilson Center-Comexi.[Consulta: 13/8/2016]. Disponible en: www.wilsoncenter.org.

MEXICO, 2012. Ley Federal de Archivos. Diario Oficial de la Federación [en línea]. [Consulta: 12/8/2016]. Disponible en: http:/ / dof.gob.mx/nota detalle.php? codigo $=5230610 \&$ fecha $=23 / 01 / 2012$

MONCRIEFFE, Joy Marie, 1998. Reconceptualizing Political Accountability. International Political Science Review, 19(4).

MORLINO, Leonardo, 2002. What is a good democracy? Theory and empirical analysis. Berkeley, University of California, Ponencia.

RED POR LA RENDICIÓN DE CUENTAS, 2014. Programa Especial de Rendición de Cuentas del Gobierno Federal (2014-2018). México: CIDE.

SUBRAMANIAM, V., 1983 Public Accountability: Context, Career and Confusions of a Concept. Indian Journal of Public Administration, 29(3). ISBN: 978-3-7705-5632-8. UGALDE, Luis Carlos, 2002. Rendición de cuentas y democracia. El caso de México. México: IFE. ISBN: 970-695-018-4. 